\title{
Teocomunicação
}

Revista de Teologia da PUCRS

Programa de Pós-Graduação em Teologia

Escola de Humanidades

Porto Alegre, v. 47, n. 2, p. 111-124, julho-dezembro 2017

doi" http://dx.doi.org/10.15448/0103-314X.2017.2.26858

PLURALISMOS

\section{Abordagens filosóficas sobre Deus}

\section{Philosophical approaches about God}

\section{Francisco de Aquino Júnior*}

\section{RESUMO}

O artigo trata da problemática da abordagem filosófica sobre Deus, destacando sua importância na filosofia e apresentando, a partir de filósofos de diferentes épocas e diferentes perspectivas, três modelos teóricos de abordagem filosófica sobre Deus: abordagem cosmológica ou naturalista (Tomás de Aquino), abordagem antropológico-subjetivista (René Descartes) e abordagem práxica (Xavier Zubiri). De cada uma dessas abordagens o artigo explicita suas características fundamentais, apresenta sua formulação em determinado filósofo e conclui com uma apreciação crítica.

Palavras-Chave: Deus. Filosofia. Modelos teóricos.

\section{ABSTRACT}

The article deals with the problematic of the philosophical approach about God, emphasizing its importance in philosophy and presenting, from philosophers of different epochs and perspectives, three theoretical models of philosophical approach about God: cosmological or naturalistic (Thomas Aquinas), anthropological-subjectivist (René Descartes) and praxical (Xavier Zubiri). From each of these approaches the article explains its fundamental characteristics, presents its formulation in a certain philosopher and concludes with a critical appreciation.

KEYWORDS: God. Philosophy. Theoretical models.

\footnotetext{
* Licenciado em filosofia pela Universidade Estadual do Ceará (UECE); doutor em teologia pela Westfälische Wilhelms-Universität Münster - Alemanha; professor da Faculdade Católica de Fortaleza (FCF) e da Universidade Católica de Pernambuco (UNICAP).
} 


\section{INTRODUÇÃO}

A filosofia sempre se confrontou com a problemática de Deus. Este é um dos seus temas centrais. Aliás, a origem da filosofia está estreitamente ligada à religião ${ }^{1}$. Seja na medida em que submetia os mitos religiosos a uma crítica racional, constituindo-se em sentido estrito como mito-logia ou teo-logia. Seja na medida em que se desenvolvia num contexto cultural profundamente marcado por uma visão religiosa do mundo que oferecia não só problemas a serem pensados, mas, mais radicalmente, a inspiração e o horizonte em que esses problemas poderiam ser pensados. A tal ponto que "no seu recurso crítico à tradição religiosa, a filosofia vinculou a legitimidade do falar sobre Deus à demonstrabilidade da [sua] função de arché"2 da realidade. E nem poderia ser diferente, uma vez que o homem antigo era essencialmente religioso.

Essa problemática de Deus atravessa toda a história da filosofia ocidental e está muito presente na atualidade ${ }^{3}$. É um tema tratado por praticamente todos os filósofos, ainda que a modo de negação. E é um tema essencial e radical, na medida em que diz respeito, positiva ou negativamente, à ultimidade e à radicalidade da reflexão filosófica.

Não vamos tratar, aqui, evidentemente, das diferentes compreensões de Deus e das diferentes argumentações sobre Deus desenvolvidas ao longo da história da filosofia. Nem temos competência para isto, nem seria possível fazê-lo num trabalho como este. Nossa pretensão é mais modesta e tem um caráter didático voltado para o ensino da filosofia. Queremos simplesmente esboçar o que consideramos as linhas ou vias fundamentais de abordagem, argumentação ou justificação filosófica sobre Deus percorridas ou desenvolvidas pela tradição filosófica ocidental.

$\mathrm{Na}$ Crítica da Razão Pura, depois de investigar os princípios apriorísticos da sensibilidade: espaço e tempo (estética transcendental) e os elementos apriorísticos do entendimento: quantidade, qualidade, relação e modalidade (analítica transcendental), Kant se confronta com a possibilidade do conhecimento metafísico: alma, universo e ser supremo (dialética transcendental) ${ }^{4}$. No que diz respeito ao conhecimento de Deus, Kant identifica e refuta na tradição ocidental três tipos de provas racionais da existência de Deus: "prova ontológica", "prova cosmológica" e "prova físico-teológica" então, tornou-se comum falar de três vias, justificações, provas ou argumentos racionais da existência de Deus: cosmológico, ontológico, teleológico ${ }^{6}$. No fundo, eles se reduzem a dois tipos de argumentos, uma vez que o argumento teleológico diz respeito à ordem ou à finalidade do mundo natural e, assim, pode ser tomado como mais uma variante do argumento cosmológico.

Já Antonio González, influenciado por Zubiri e Ellacuría, fala de duas formas clássicas de justificação racional de Deus na filosofia: "naturalista" e "subjetivista". E, a partir das críticas feitas e desenvolvidas sobre essas formas de justificação filosófica de Deus, indica uma terceira forma: justificação "práxica" . Esta não parte

\footnotetext{
${ }^{1}$ Cf. JAEGER, W. La teologia de los primeiros filósofos griegos; LIMA VAZ, H. C. "Teologia medieval e cultura moderna”, p. 71-86; PANNENBERG, W. Filosofia e Teologia, p. 9-16.

${ }^{2}$ Cf. PANNENBERG, W. Filosofia e teologia, p. 12.

${ }^{3}$ Cf. CORETH, E. Deus no pensamento filosófico; JORDAN, J. (org.). Filosofia da Religião; PENZO, G.; GIBELLINI, R. Deus na filosofia do século XX; OLIVEIRA, M.; ALMEIDA, C. (orgs.). O Deus dos filósofos modernos; OLIVEIRA, M.; ALMEIDA, C. (orgs.). O Deus dos filósofos contemporâneos.

${ }^{4}$ Cf. KANT, I. Crítica da Razão Pura.

${ }^{5}$ Cf. KANT, I. Crítica da Razão Pura, p. 364-393.

${ }^{6}$ Cf. ANZENBACHER, A. Introdução à filosofia ocidental, p. 340ss; WILKINSON, M. B.; CAMPBELL, H. N. Filosofia da religião, p. 136-207; ROWE, W. L. Introdução à filosofia da religião, p. 39-107.

Cf. GONZÁLEZ, A. Introducción a la práctica de la filosofia, p. 353-400.
} 
nem da natureza (justificação naturalista) nem da consciência (justificação subjetivista), mas da interação do homem com o mundo ou da ação humana (justificação práxica).

Teríamos, assim, três tipos fundamentais de abordagem filosófica sobre Deus: abordagem cosmológica ou naturalista, abordagem antropológico-subjetivista (já que existem várias formas de abordagem antropológica: inteligência, vontade, sentimento etc.) e abordagem práxica. Certamente, cada uma dessas abordagens tem uma variedade enorme de elaboração e formulação que aqui não podemos sequer indicar. E é possível que haja ou que se possa desenvolver outras abordagens que extrapolem essas formas acima indicadas, constituindo-se como novos tipos de abordagem filosófica sobre Deus. Em todo caso, não há dúvida de que a grande maioria das abordagens sobre Deus na história da filosofia pode ser qualificada como abordagens naturalistas ou antropológicas ou práxicas. Sem falar no caráter sistemático e didático-pedagógico dessa apresentação da problemática de Deus na filosofia.

E esta é a estrutura fundamental de nosso texto: abordagem cosmológica ou naturalista; abordagem antropológico-subjetivista; abordagem práxica. Em cada uma dessas abordagens, começaremos explicitando suas características fundamentais, apresentaremos sua formulação em um determinado filósofo e concluiremos com uma apreciação crítica dessa abordagem. Na escolha do filósofo para cada abordagem, levamos em conta sua importância e representatividade na referida abordagem, mas consideramos também diversos períodos da história da filosofia: medieval, moderno, contemporâneo. Assim, apresentaremos as formulações de Tomás de Aquino (abordagem cosmológica ou naturalista), de Descartes (abordagem antropológico-subjetivista) e de Xavier Zubiri (abordagem práxica).

\section{ABORDAGEM COSMOLÓGICA OU NATURALISTA}

\subsection{Caracterização}

Trata-se da maneira mais clássica de formular o problema de Deus da filosofia. Remonta aos inícios mesmos da filosofia na Grécia, é radicalizada na filosofia aristotélica e retomada e reelaborada pela filosofia medieval.

Esta forma de abordagem filosófica de Deus parte da estrutura do cosmos/universo ou, mais precisamente, de um conjunto de teses ou hipóteses sobre ele (movimento, causalidade, contingência, graus de ser, ordem/finalidade) para, a partir daí, demonstrar racionalmente a existência ou a necessidade da existência de Deus (motor imóvel, causa primeira, ser necessário, ser supremo, inteligência suprema).

Fala-se, aqui, de argumento cosmológico ou de justificação naturalista porque toma como ponto de partida e como referencial teórico-conceitual de sua reflexão e argumentação o cosmos ou a natureza ou um conjunto de hipóteses ou uma determinada compreensão do cosmos ou da natureza.

$\mathrm{Na}$ formulação de Kant na Crítica da razão pura: "A prova começa propriamente com a experiência, por conseguinte, não procede totalmente a priori ou ontologicamente, e visto que o objeto de toda experiência possível denomina-se mundo, a prova é denominada cosmológica"s.

Segundo Xavier Zubiri, “a filosofia e sobretudo a teologia clássica partiram da realidade considerada como isso que chamamos natureza [...]. Daí que tomaram como

${ }^{8}$ KANT, I. Crítica da Razão Pura, p. 374. 
base de sua discussão a estrutura do cosmos; e se propuseram fundamentar a existência de Deus com argumentos tomados de fatos cósmicos"».

Dentre as diversas formulações desse tipo de abordagem ou argumento, destacamse as famosas "cinco vias" de prova ou demonstração da existência de Deus de Tomás de Aquino, teólogo-filósofo do século XIII ${ }^{10}$.

\subsection{Formulação em Tomás de Aquino (1225-1274)}

Antes de tudo, é importante ter presente que as "cinco vias" para provar ou demonstrar a existência de Deus encontram-se na Suma Teológica $(S T)^{11}$ e que, como adverte Coreth, "essas demonstrações da existência de Deus já estão de antemão dentro do horizonte da fé e pressupõem, por isso, uma compreensão 'do que denominamos Deus" "12, embora seja preciso ou conveniente demonstrá-la racionalmente.

É importante também atentar para o modo como Tomás estrutura sua reflexão na $S T$ - uma maneira típica de seu tempo e bem distante da nossa. A $S T$ está dividida em três partes. Cada parte é composta por várias questões. E cada questão está dividida em vários artigos. Cada artigo começa indicando o problema a ser tratado em forma de questão; apresenta as objeções à tese defendida e os argumentos contrários a essas objeções; desenvolve a posição ou a resposta de Tomás ao problema em questão; e, a partir da resposta, replica às objeções inicialmente indicadas ${ }^{13}$.

O texto que nos interessa, aqui, as chamadas "cinco vias", é a resposta do artigo 3 da questão 2 da I parte da $S T$ que trata da existência de Deus (ST I, q. 2, a. 3, resp.). Não vamos fazer uma apresentação geral do artigo, mas apenas da resposta que Tomás de Aquino dá a esse problema ou, mais precisamente, da estrutura de seu argumento ${ }^{14}$.

Ele começa afirmando que "pode-se provar a existência de Deus por cinco vias" e passa, imediatamente, a apresentar essas cinco vias.

A primeira via "15 "parte do movimento": "nossos sentidos atestam que neste mundo algumas coisas se movem"; "mover nada mais é do que levar algo da potência ao ato"; "é preciso que tudo que se move seja movido por outro"; "não se pode continuar até o infinito, pois neste caso não haveria um primeiro motor, por conseguinte, tampouco outros motores"; "é então necessário chegar a um primeiro motor, não movido por nenhum outro, e um tal ser, todos entendem: é Deus".

A segunda via 16 "parte da razão de causa eficiente": "encontramos nas realidades sensíveis uma ordem entre as causas eficientes"; "mas não se encontra algo que seja a causa eficiente de si próprio, porque desse modo seria anterior a si próprio, o que é impossível"; e não se pode "continuar até o infinito" porque "se não existisse a primeira

\footnotetext{
${ }_{9}^{2}$ ZUBIRI, X. El hombre y Dios, p. 118.

${ }_{10}$ "No que se sabe de sua vida, de seus estudos e de sua obra, nada autoriza a pensar que ele mesmo jamais se considerasse um filósofo nem que ele tenha nutrido a ambição de ter uma filosofia pessoal" (GILSON, E. Introdução à filosofia cristã, p. 47); "como teólogo, o único objetivo de seu esforço é o de construir uma teologia, não uma filosofia" (GILSON, E. Introdução à filosofia cristã, p. 59).

${ }^{11}$ Cf. TOMÁS DE AQUINO. Suma Teológica.

${ }^{12}$ CORETH, E. Deus no pensamento filosófico, p. 162.

${ }^{13}$ Cf. WILKINSON, M. B. - CAMPBELL, H. N. Filosofia da religião, p. 160.

${ }^{14}$ Cf. CORETH, E. Deus no pensamento filosófico, p. 160-163; WILKINSON, M. B.; CAMPBELL, H. N. Filosofia da religião, p. 160-168, 184s, 198s; ROWE, W. L. Introdução à filosofia da religião, p. 40s; GONZÁLEZ, A. Introducción a la práctica de la filosofia, p. 355.

${ }^{15}$ Esse argumento está baseado em Aristóteles. "Talvez a contribuição mais importante de Aristóteles às teorias da existência de Deus seja sua noção de Deus como primeiro motor" que será retomada por Tomás como a primeira de suas "cinco vias" (WILKINSON, M. B.; CAMPBELL, H. N. Filosofia da religião, p. 81).

${ }^{16}$ Também aqui, Tomás recorre a Aristóteles com sua teoria das quatro causas. "Na qualidade de um observador atento ao mundo [filho de médico], Aristóteles acreditava nas noções de causa e efeito. Desenvolveu o conceito amplamente na Física, mas a ideia é central em toda a sua obra. Identificou quatro tipos de causa que fazem algo ser o que é": causa material [aquilo de que algo é feito], causa formal [forma ou formato que algo recebe], causa eficiente [aquilo/aquele que faz algo], causa final [finalidade] (WILKINSON, M. B.; CAMPBELL, H. N. Filosofia da religião, p. 79s).
} 
entre as causas eficientes, não haveria a última nem a intermediária" e, "supressa a causa, suprime-se também o efeito"; "logo, é necessário afirmar uma causa eficiente primeira a que todos chamam Deus".

A terceira via17 "é tomada do possível e do necessário": "encontramos, entre as coisas, as que podem ser ou não ser" (nascem e perecem); "o que pode não ser não é em algum momento"; "se tudo pode não ser, houve um momento em que nada havia"18; "se isso é verdadeiro, ainda agora nada existiria, pois o que não é só passa a ser por intermédio de algo que já é"; "assim, nem todos os entes são possíveis, mas é preciso que algo seja necessário entre as coisas"; "aqui também não se pode continuar até o infinito" e "é necessário afirmar a existência de algo por si mesmo [...] que é a causa da necessidade para os outros: o que todos chamam Deus".

A quarta via" "se toma dos graus que se encontram nas coisas": "encontra-se nas coisas algo mais ou menos bom, verdadeiro, nobre etc."; "mais ou menos se diz de coisas diversas conforme elas se aproximam diversamente daquilo que é em si o máximo"; "existe em grau supremo algo verdadeiro, bom, nobre e, consequentemente, o ente em grau supremo", pois "o que é em sumo grau verdadeiro, é ente em supremo grau" e "o que se encontra no mais alto grau em determinado gênero é causa de tudo que é desse gênero"; "existe então algo que é, para todos os entes, causa de ser, de bondade e de toda perfeição: nós o chamamos Deus".

A quinta via "é tomada do governo das coisas": "vemos que algumas coisas que carecem de conhecimento agem em vista de um fim - sempre ou na maioria das vezes agem da mesma maneira a fim de alcançarem o que é ótimo"; "não é por acaso, mas em virtude de uma intensão que alcançam o fim"; "aquilo que não tem conhecimento não tende a um fim, a não ser dirigido por algo que conhece e que é inteligente, como a flecha pelo arqueiro"; "logo, existe algo inteligente pelo qual as coisas naturais são ordenadas ao fim e a isso nós chamamos Deus".

No fundo, essas cinco vias têm a mesma estrutura argumentativa: partem do que se consideram fatos incontestáveis, atestados pelos sentidos, cuja explicação racional exige ou leva necessariamente a afirmação da existência de Deus como explicação última desses supostos fatos.

\footnotetext{
17 "Nesse argumento vemos claramente a influência de Boécio [...]. O argumento de Tomás, em essência, parece ser que todas as coisas em nossa experiência são contingentes, mas nem todas as coisas podem ser contingentes. Deve haver alguma coisa necessária, independente de qualquer outra coisa, da qual todas as demais dependem" (WILKINSON, M. B.; CAMPBELL, H. N. Filosofia da religião, p. 165). "Boécio, em seu Comentário às Categorias de Aristóteles, argumenta que todas as coisas que podemos pensar acontecem em uma ou mais das quatro categorias: pode existir, pode não existir, não pode existir, não pode não existir" (WILKINSON, M. B.; CAMPBELL, H. N. Filosofia da religião, p. 141).

${ }^{18}$ Essa passagem de coisas contingentes à contingência de tudo supõe, sem dúvida, a fé na criação de todas as coisas por Deus ou a fé no Deus criador de todas as coisas.

19 “O quarto caminho é de procedência platônica e mostra que há nas coisas degraus de perfeição" (CORETH, E. Deus no pensamento filosófico, p. 161). A propósito do exemplo do fogo: "De maneira tão condensada que seu procedimento permanece obscuro, tal raciocínio evoca o grande tema metafísico da participação, que não provém de Aristóteles, mas de Platão, e que, profundamente remodelado pela introdução da causalidade eficiente e da limitação do ato pela potência - estas sim provenientes de Aristóteles - está no centro da metafísica de Sto. Tomás" (NICOLAS, J.-H. “O Deus único: introdução e notas", p. 168, n. K). O argumento de Tomás parte da "suposição da Metafísica de Aristóteles de que há uma correlação entre a verdade maior e ser maior" (WILKINSON, M. B.; CAMPBELL, H. N. Filosofia da religião, p. 198). No fundo, esta essa via articula a teoria da participação de tradição (neo)platônica com as teorias aristotélicas da causalidade eficiente e da correlação entre verdade maior e ser maior e a verdade de fé da criação de todas as coisas por Deus.

20 "Esse argumento diz respeito ao design em vista de um fim - as coisas estão dispostas juntas para terem uma função. Aqui vemos diretamente a influência da noção aristotélica de que a natureza é teleológica, onde as coisas agem em vista de um fim" (WILKINSON, M. B.; CAMPBELL, H. N. Filosofia da religião, p. 185). Vale recordar, aqui, a teoria da causalidade, concretamente a causa final (Cf. WILKINSON, M. B.; CAMPBELL, H. N. Filosofia da religião, p. 80). Para Kant, essa prova, que ele denomina físico-teológica, "merece sempre ser citada com respeito. Trata-se da mais antiga, mais clara e mais conforme com a razão humana comum" (KANT, I. Cítica da Razão Pura, p. 384).
} 


\subsection{Apreciação crítica}

Sem dúvida, o raciocínio ou argumento de Tomás de Aquino nas "cinco vias" é muito lógico e nisso reside sua força e seu poder de convencimento. Mas ele repousa sobre determinados pressupostos que se tornaram problemáticos ou, pelo menos, deixaram de ser evidentes no mundo moderno. Pressupostos que, como sintetiza e indica Xavier Zubiri, dizem respeito tanto ao ponto de partida (fatos cósmicos?), quanto ao ponto de chegada (Deus?) de sua argumentação ${ }^{21}$.

Ele parte do que considera fatos atestados pelos sentidos. Mas o que ele considera fatos, na verdade, não são senão uma interpretação ou teoria físico-metafisica da realidade sensível, de cunho aristotélico, que deixou de ser evidente e se tornou problemática sob muitos aspectos ${ }^{22}$, como se pode ver, inclusive, em comentários um tanto "devotos" e apologéticos ${ }^{23}$. Não é nada evidente, por exemplo, que movimento seja passagem de potência a ato, que se possa falar realmente de causalidade, que haja verdadeira finalidade no mundo natural, que o mundo seja contingente etc. A base de argumentação de Tomás não são, como ele indica, fatos, mas a metafísica de Aristóteles, por mais que seja reelaborada a partir e em função da doutrina cristã. E "não se deve ignorar uma certa unilateralidade nessas demonstrações. A ligação estreita com Aristóteles exclui um outro acesso a Deus mais derivado do homem, tal como é próprio do pensamento de Agostinho e ainda desenvolvido por Boaventura"24.

Também o ponto de chegada de seu argumento é bastante problemático ${ }^{25}$. E num duplo sentido, como indica Zubiri. Antes de tudo, haveria que ver se "estas cinco 'primariedades' [motor imóvel, causa primeira, algo necessário, algo supremo, algo inteligente] se identificam entre si em um mesmo ente". E, mesmo que se provasse essa identificação, "isto não significa que se provou sem mais que esse ente supremo seja formalmente Deus, o que entendemos por Deus" ${ }^{26}$. Há, aqui, como que um salto não justificado que identifica sem mais o ponto de chegada desses argumentos com o Deus cristão. E isso não é nada evidente, como supõe Tomás de Aquino.

\section{ABORDAGEM ANTROPOLÓGICO-SUBJETIVISTA}

\subsection{Caracterização}

Diferentemente da abordagem cosmológica ou naturalista, temos, aqui, uma abordagem que em certo sentido pode ser dita antropológica, já que parte do homem como realidade distinta do cosmos. Mas, como o homem é uma realidade complexa, constituídas por múltiplas dimensões, esse tipo de abordagem recebeu diferentes configurações a partir de diferentes dimensões da vida humana. Por exemplo: inteligência (Agostinho), vontade (Kant), sentimento (Schleiermacher) ${ }^{27}$.

Vamos tratar de uma dessas abordagens "antropológicas" da existência de Deus que parte da dimensão inteligente da vida humana e que é nomeada de várias formas: argumento anselmiano, argumento a priori, argumento ontológico, argumento subjetivista.

\footnotetext{
${ }^{21}$ Cf. ZUBIRI, X. El hombre y Dios, p. 118-123.

${ }^{22}$ Cf. ZUBIRI, X. El hombre y Dios, p. 119-121.

${ }^{23}$ Cf. NOUGUÉ, C. "Apresentação", p. 25-69, aqui p. 49-63.

${ }^{24}$ CORETH, E. Deus no pensamento filosófico, p. $162 \mathrm{~s}$.

${ }^{25}$ Cf. ZUBIRI, Xavier. El hombre y Dios, p. $121 \mathrm{ss}$; Cf. CORETH, E. Deus no pensamento filosófico, p. 162; ROWE, William L. Introdução à filosofia da religião, p. 40s. GILSON, E. Introdução à filosofia cristã, p. 42s.

${ }^{26}$ ZUBIRI, X. El hombre y Dios, p. 122.

${ }^{27}$ Cf. ZUBIRI, X. El hombre y Dios, p. 123s.
} 
Ela será formulada, aqui, em termos de argumento antropológico-subjetivista. Sua característica principal consiste em ser um argumento "a priori”, no qual "a definição verdadeira de Deus necessariamente requer sua existência, exatamente como a definição de um quadrado necessariamente requer que tenha quatro lados"28.

Enquanto a abordagem cosmológico-naturalista partia da estrutura do cosmos/ universo ou de um conjunto de teses ou hipóteses sobre ele para, a partir daí, demonstrar racionalmente a existência de Deus, a abordagem antropológicosubjetivista, prescindindo de toda experiência do mundo, busca demonstrar a existência de Deus a partir da ideia mesma de Deus como ser supremo e/ou ser perfeitíssimo. Por isso mesmo, fala-se, aqui, de argumento ou justificação a priori: um "conhecimento que não depende da experiência sensível, mas do significado das palavras" 29 .

Embora seja sempre referido a Anselmo (1033-1109) ou à sua definição de Deus como o "ser acima do qual nada maior podemos pensar"30, como adverte Coreth, "a formulação não é novidade de Anselmo, encontra-se de forma semelhante em Cícero, Sêneca, Agostinho e Boécio. Nova, no entanto, é a interpretação de que aí a existência de Deus está conceitualmente contida"31. Ela será retomada por Descartes, no contexto da crise da metafísica clássica e do nascimento da modernidade.

\subsection{Formulação em Descartes (1596-1650)}

Não se sabe ao certo se Descartes conhecia o argumento de Anselmo, embora seja muito provável e ele mesmo parece ter dado a entender a amigos que sim. Em todo caso, seu argumento é similar ao de Anselmo, tanto em seu caráter "a priori", quanto "em sua suposição de que a existência é intrínseca à definição de Deus"32.

Mas o contexto é bem diferente. Descartes marca o início de uma grande virada na filosofia que, séculos depois, será reconhecida e nomeada por Kant como uma verdadeira "revolução copernicana" no pensamento ocidental, o que significa que, em vez da "intuição" ser regulada pela "natureza do objeto", como acontecia na filosofia antiga e medieval, o "objeto" passa a ser regulado pela "natureza de nossa faculdade de intuição" 33 . Não por acaso Descartes é considerado pai da filosofia moderna.

“A consciência e não a natureza é o novo ponto de partida da filosofia". E neste contexto, claro, "as provas e demonstrações da existência de Deus já não vão se fundar em uma descrição do universo natural, mas na consciência e na razão humana”. Noutras palavras: "a filosofia se torna subjetivista e, consequentemente, também se subjetivisa o problema de Deus" ${ }^{34}$.

No centro das preocupações de Descartes está a busca de um conhecimento certo e verdadeiro, do qual não se possa duvidar. No Discurso do método (1637) e nas Meditações filosóficas (1641) ele expõe o caminho/método e os princípios desse conhecimento certo e verdadeiro. Começa duvidando de tudo (dúvida metódica) até chegar a algo do qual não se possa mais duvidar e no qual se possa fundar um conhecimento certo: posso

\footnotetext{
${ }^{28}$ WILKINSON, M. B.; CAMPBELL, H. N. Filosofia da religião, p. 137.

${ }^{29}$ WILKINSON, M. B.; CAMPBELL, H. N. Filosofia da religião, p. 76.

${ }^{30} \mathrm{Cf}$. ANSELMO DE CANTUÁRIA. Proslógio, p. 44-47.

${ }^{31}$ CORETH, E. Deus no pensamento filosófico, p. 146; Cf. ANZERBACHER, A. Introdução à filosofia ocidental, p. 354.

${ }^{32}$ WILKINSON, M. B.; CAMPBELL, H. N. Filosofia da religião, p. 146.

${ }^{33}$ KANT, I. Crítica da razão pura, p. 39.

${ }^{34} \mathrm{GONZÁ} L E Z$, A. Introducción a la práctica de la filosofia, p. 356.
} 
duvidar de tudo (sentidos, ideias), mas não posso duvidar de que, quando duvido, existo (cogito, ergo sum $)^{35}$.

Partindo dessa certeza subjetiva, ele se esforça para demonstrar a existência do mundo objetivo. Mas para isso tem que recorrer a Deus que, sendo verdadeiro e poderoso, não permite que nos enganemos. Antes de demonstrar a existência de uma realidade objetiva, tem, portanto, que demonstrar a existência de Deus. E não pode fazer isso recorrendo à natureza, como faz, por exemplo, Tomás de Aquino. Pelo contrário. Tem que demonstrar a existência de Deus "prescindindo da realidade do mundo, da qual não temos certeza verdadeira até que estejamos seguros da realidade de Deus". Para isto, "recorrerá a várias provas, dentre elas o chamado argumento anselmiano ou argumento ontológico"36, como aparece na Quinta Meditação.

Em suas Meditações ${ }^{37}$, "Descartes tenta reconstruir todo o conhecimento a partir dos [seus] princípios primeiros"38; ele tentar apresentar os princípios ou os fundamentos de um conhecimento certo e verdadeiro: A primeira meditação trata "das coisas que se podem colocar em dúvida" (dúvida metódica); a segunda trata "da natureza do espírito humano e de como ele é mais fácil de conhecer do que o corpo" (cogito, ergo sum); a terceira trata "de Deus, que ele existe" (existência de Deus como realidade objetiva); a quarta trata "do verdadeiro e do falso" (possibilidade do erro); a quinta trata "da essência das coisas materiais e, novamente, de Deus e de sua existência" (ideias matemáticas e argumento ontológico); e a sexta trata "da existência das coisas materiais e da distinção real entre a alma e o corpo do homem" (coisas materiais).

Quanto à Quinta Meditação, onde aparece o chamado "argumento ontológico", começa com o "exame das ideias das essências" (§§ 1-2), prossegue com a "validação da verdade das essências matemáticas" ( $\S 3-6)$, apresenta a "prova ontológica" $(\S \S 7-10)$ e conclui indicando as "vantagens desta nova prova" (§§ 11-15)

$\S \S 1-2$ : "Ver se não é possível conhecer nada de certo no tocante às coisas materiais"; consideração prévia das "ideias" que se encontram no "pensamento" para ver "quais são distintas e quais são confusas".

§§ 3-6: Ideia de "quantidade" (extensão, partes, duração); "infinidade de particularidades" (números, figuras, movimentos); essas ideias "possuem suas naturezas verdadeiras e imutáveis" (por exemplo, em todo triângulo "os três ângulos são iguais a dois retos" e "o maior ângulo é oposto ao maior lado"); infinidade de outras ideias claras e distintas da aritmética e da geometria que não passam pelos sentidos.

$\S \S 7-10:$ Argumento/prova da existência de Deus: "ideia de um ser soberano e perfeito", a cuja "natureza" pertence "uma existência atual e eterna"; embora se possa "em todas as coisas fazer distinção entre a existência e a essência", "a existência não pode ser separada da essência de Deus"; "do simples fato de eu não poder conceber Deus sem existência, segue-se que a existência lhe é inseparável e, portanto, que existe verdadeiramente"; sempre que "pensar em um ser primeiro e soberano [...] é necessário que eu lhe atribua todas as espécies de perfeição [...] esta necessidade é suficiente para me fazer concluir [...] que este ser primeiro e soberano existe verdadeiramente"; "esta ideia [...] é a imagem de uma natureza verdadeira e imutável": só em Deus a existência pertence à essência, só é possível conceber um Deus dessa maneira, não posso diminuir nem mudar nada em Deus.

\footnotetext{
${ }^{35}$ Cf. WILKINSON, M. B.; CAMPBELL, H. N. Filosofia da religião, p. 144. Essa forma de argumentar já se encontra em Agostinho (Cf. SANTO AGOSTINHO. A Trindade, X, 10).

${ }^{36} \mathrm{GONZÁLEZ,} \mathrm{A.} \mathrm{Introducción} \mathrm{a} \mathrm{la} \mathrm{práctica} \mathrm{de} \mathrm{la} \mathrm{filosofia,} \mathrm{p.} 356$.

${ }^{37}$ DESCARTES, R. Meditações, p.75-142.

${ }^{38}$ WILKINSON, M. B.; CAMPBELL, H. N. Filosofia da religião, p. 144.

${ }^{39}$ Cf. LEBRUN, G. "Prefácio e notas", p. 131, nota 130.
} 
$\S \S$ 11-15: "São somente as coisas que concebo clara e distintamente que têm a força de me persuadir inteiramente": algumas "conhecidas de qualquer" pessoa e outras conhecidas apenas "por aqueles que as consideram mais de perto e que as examinam mais exatamente" (triângulo retângulo, Deus); "a certeza de todas as outras coisas depende tão absolutamente [da certeza de Deus] que, sem esse conhecimento, é impossível jamais conhecer algo perfeitamente"; "se eu ignorasse que há um Deus [...] eu jamais teria uma ciência verdadeira e certa de qualquer coisa que seja, mas somente opiniões vagas e inconstantes"; "a certeza e a verdade de toda ciência depende do tão só conhecimento do verdadeiro Deus [...] e, agora que o conheço, tenho o meio de adquirir uma ciência perfeita no tocante à uma infinidade de coisas".

A estrutura do argumento de Descartes é muito clara: parte de uma infinidade de ideias claras e distintas em seu pensamento; reconhece que essas ideias possuem suas naturezas verdadeiras e imutáveis; entre essas ideias está a ideia de Deus como ser soberano e perfeito; a um ser perfeito pertencem todas as perfeições e, portanto, também a existência atual e eterna; logo, Deus existe necessariamente.

\subsection{Apreciação crítica}

Vários filósofos se confrontaram com esse tipo de abordagem que, especialmente a partir de Anselmo, marca decisivamente o debate filosófico sobre Deus. A crítica a esse tipo de argumento pode ser resumida em duas questões fundamentais: salto do ideal para o real e existência como predicado.

Uma primeira questão tem a ver com a passagem automática do mundo ideal para o mundo real. A crítica já aparece na reação ao Proslógio de Anselmo feita pelo beneditino Gaunilo em seu Livro escrito a favor de um insensato ${ }^{40}$. É retomada por Tomás de Aquino na $S T$ ao se perguntar "se a existência de Deus é evidente por si mesma"41, por Kant, em sua crítica ao chamado "argumento antológico"42, e por muitos outros. O cerne da crítica, como indica Coreth, consiste na tese de que "a realidade (esse in re) contida no pensamento do ser superior a tudo é mesmo assim somente uma realidade pensada (esse in intellectu), que não se aproxima da existência real de Deus. Portanto, de fato, um salto do pensamento para o ser real"43. Nas palavras de Antonio González, "Descartes passa com demasiada rapidez de uma dedução ideal (a ideia de um ser perfeito inclui sua existência) a uma conclusão real: esse ser perfeito existe". Isso só é possível partindo do pressuposto racionalista de uma "correspondência perfeita" entre "a ordem ideal e a ordem real", o que não é tão evidente assim ${ }^{44}$.

Uma segunda questão, formulada por Kant, tem a ver com a compreensão de existência como predicado: "Ser evidentemente não é um predicado real, isto é, um conceito de qualquer coisa que possa ser acrescido ao conceito de outra coisa [...]. Portanto, quando penso uma coisa [...], o fato de eu ainda acrescentar que essa coisa é não acrescenta nem um pouquinho à coisa" ${ }^{45}$. Noutras palavras, uma prova ontológica não é possível porque "a existência não é um predicado". Na verdade, "quando dizemos que uma coisa existe, não estamos dizendo nada de novo sobre os conteúdos de sua realidade", mas simplesmente que "minha descrição corresponde a um objeto real"

\footnotetext{
${ }^{40} \mathrm{Cf}$. GAUNILO. "Livro escrito a favor de um insensato", p. 83-93.

${ }^{41}$ Cf. TOMÁS DE AQUINO. Suma Teológica I, q. 2, a. 1.

${ }^{42}$ KANT, I. Cítica da Razão Pura, p. 368-373.

${ }^{43}$ CORETH, E. Deus no pensamento filosófico, p. $271 \mathrm{~s}$.

${ }^{44} \mathrm{GONZÁLEZ,} \mathrm{A.} \mathrm{Introducción} \mathrm{a} \mathrm{la} \mathrm{práctica} \mathrm{de} \mathrm{la} \mathrm{filosofia,} \mathrm{p.} \mathrm{356s.}$

${ }^{45}$ KANT, I. Crítica da Razão Pura, p. 371s.

${ }^{46}$ GONZÁLEZ, A. Introducción a la práctica de la filosofia, p. 358.
} 
Sem falar que inteligência não se reduz a consciência e não existe nem pode ser compreendida independentemente das outras dimensões da vida humana: vontade, sentimento etc. Nem a vida humana pode ser compreendida independentemente ou, pior, em oposição ao cosmos ou à natureza. Não existe o homem enquanto tal nem muito menos a inteligência enquanto tal. É sempre a tentação das chamadas vias antropológicas: contrapor o homem à natureza e isolar e substantivar determinada dimensão da vida humana ${ }^{47}$.

\section{ABORDAGEM PRÁXICA}

\subsection{Caracterização}

Este tipo de abordagem é relativamente recente e está ligada à descoberta da historicidade da vida e do pensamento e, mais concretamente, ao desenvolvimento das filosofias da práxis em seu esforço de superação dos reducionismos cosmológicos e antropológicos que marcam a história da filosofia.

Diferentemente da abordagem cosmológico-naturalista que parte do cosmos ou da natureza como realidade distinta do homem e da abordagem antropológico-subjetivista que parte do homem ou mais precisamente da dimensão inteligente da vida humana em contraposição ao cosmos ou à natureza, a abordagem práxica parte da interação do homem com o mundo.

Seu ponto de partida, portanto, nem é o cosmos nem o homem, tomados isoladamente e/ou em contraposição um ao outro, mas a ação humana estruturada por uma dupla dimensão: dimensão subjetiva e dimensão natural. Na práxis humana, a realidade intramundana aparece como um todo constituído por múltiplos aspectos ou dimensões em respectividade uns aos outros; um todo coerente e sistematicamente estruturado, no qual as diversas dimensões que o constituem nem existem isoladamente nem se reduzem umas às outras.

A questão, aqui, consiste em saber se a ação humana ou a práxis, enquanto interação do homem com o mundo, implica, de alguma forma e em alguma medida, um problema de Deus enquanto fundamento último da realidade em seu todo. Noutras palavras, tratase de ver se a práxis tem uma estrutura estritamente teologal, isto é, se em si mesma envolve e remete a Deus.

Certamente, nem todas as filosofias da práxis apreenderam e explicitaram adequadamente a estrutura teologal da práxis. Muitas vezes, a práxis foi reduzida à sua dimensão política em oposição ou mesmo em contraposição às múltiplas dimensões que a constituem, estruturam e dinamizam, particularmente à sua dimensão teologal.

Ao falarmos de abordagem práxica de Deus nos situamos, aqui, concretamente, na tradição filosófica de Xavier Zubiri, filósofo espanhol, e em seu desenvolvimento por Ignacio Ellacuria ${ }^{48}$ e Antonio González ${ }^{49}$.

\subsection{Formulação em Xavier Zubiri (1898-1983)}

Um dos pontos mais centrais e decisivos na filosofia de Xavier Zubiri diz respeito ao que ele chamou "problema de Deus na vida humana" ou "problema teologal do

\footnotetext{
${ }^{47}$ Cf. ZUBIRI, X. El hombre y Dios, p. 123-127.

${ }^{48} \mathrm{Cf}$. ELLACURÍA, I. Filosofía de la realidade histórica.

${ }^{49} \mathrm{Cf}$. GONZÁLEZ, A. Introducción a la práctica de la filosofia, p. 369-385.
} 
homem". É a insistência em mostrar que existe na vida humana um âmbito ou uma dimensão que envolve e dá acesso à realidade de Deus, enquanto fundamento último do real. E independentemente do modo como esse fundamento seja inteligido (Deus, pura facticidade, realidade-desconhecida) e da posição que se tome diante desse problema (teísmo, ateísmo, agnosticismo).

O desenvolvimento e a exposição desse problema estão divididos em três partes que correspondem a três grandes problemas: análise filosófica do problema de Deus na vida humana (Deus); estudo filosófico da história das religiões (Religião); e estudo filosófico-teológico do cristianismo como religião de "deiformação" (Cristianismo). Toda sua reflexão sobre esta problemática desenvolvida ao longo de sua atividade filosófica foi recolhida e publicada postumamente em três tomos: O homem e Deus ${ }^{50}$; O problema filosófico da história das religiões ${ }^{51}$; O problema teologal do homem: Cristianismo ${ }^{52}$.

No que diz respeito à análise filosófica do problema de Deus na vida humana, uma questão fundamental tem a ver com o ponto de partida dessa abordagem. Zubiri rechaça tanto a "via cosmológica" quanto a "via antropológica", desenvolvidas ao longo da tradição filosófica ocidental. A primeira via lhe parece problemática seja por seu "ponto de partida" ("fatos cósmicos"?) seja por seu "ponto de chegada" ("Deus enquanto Deus"?). A segunda via também lhe parece problemática em seu ponto de partida (abordagem parcial da vida humana, abordagem dualista de cada aspecto da vida humana, contraposição do homem ao cosmos) e em seu ponto de chegada (um Deus mais ou menos segregado do mundo real) ${ }^{53}$. A insuficiência e problematicidade dessas vias impõem a "necessidade de empreender uma rota distinta". E Zubiri o fará tomando como ponto de partida a realidade humana como uma realidade que tem que se realizar a si mesma, portanto, como uma realidade fundamentalmente práxica (práxis) ou accional (ação).

$\mathrm{Na}$ apresentação dessa via desenvolvida por Zubiri, tomaremos como referência a introdução do curso que ele deu na Universidade Gregoriana de Roma, em 1973, sobre "O problema teologal do homem". Embora não seja a última elaboração de Zubiri sobre o tema, é um texto de sua última etapa, tem a vantagem de apresentar de modo sistemático, didático e resumido sua reflexão sobre o problema teologal do homem e, ademais, está traduzido em português ${ }^{54}$.

Zubiri se propõe fazer "uma análise da realidade humana enquanto tal, tomada em e por si mesma" para ver se há nesta realidade "alguma dimensão que de fato envolva, constitutiva e formalmente, um enfrentamento inexorável com a dimensão última do real, isto é, com o que de uma maneira meramente nominal e provisória podemos chamar Deus" (14). E desenvolve esta análise em "três passos" (15).

(A) Ele começa afirmando que "o homem é uma realidade não feita de uma vez por todas, mas uma realidade que tem que ir realizando-se" (15).

É que o homem, pelas notas que possui, particularmente pela inteligência, "não apenas tem realidade" (notas), mas "é uma realidade formalmente "sua' como realidade" (si mesmo), ou seja, é uma realidade pessoal. Enquanto tal, ele apreende as coisas não apenas como "estímulo de resposta", como os demais animais, mas como "realidade",

\footnotetext{
${ }^{50} \mathrm{Cf}$. ZUBIRI, Xavier. El hombre y Dios.

${ }^{51} \mathrm{Cf}$. ZUBIRI, X. El problema filosófico de la historia de las religiones.

${ }^{52} \mathrm{Cf}$. ZUBIRI, X. El problema teologal del hombre.

${ }^{53}$ Cf. ZUBIRI, X. El hombre y Dios, p. 118-127.

${ }^{54}$ Cf. ZUBIRI, X. "O problema teologal do homem”, p. 13-20. A partir de agora, os números entre parêntese, sem outra indicação, remetem a páginas deste artigo.
} 
isto é, como alteridade radical; tão radical que se impõe na vida humana: toma "posse", exerce um "poder", "domina", "move", obrigando o homem a reagir de uma forma ou de outra. Isso faz com que ele se experimente como uma realidade "ab-soluta" (desligada de qualquer outra realidade), embora "só relativamente ab-soluta" (em relação às coisas diante das quais ou "frente às" quais ela se encontra). Experimenta-se, portanto, como des-ligado de todas as coisas e, ao mesmo tempo, re-ligado ao "poder do real" que as coisas veiculam (15).

Por isso, diz Zubiri, "o homem necessita de tudo aquilo com que vive, mas aquilo de que necessita é a realidade" (15). A expressão "realidade" designa, aqui, a última determinação metafísica das coisas enquanto apreendidas pelo homem: são o que são "de suyo", "en próprio" 55 . Enquanto tal, ela constitui aquilo que, em ultima instância, "fundamenta", "possibilita" e "impele" o homem a se realizar a si mesmo. Só porque apreende as coisas como "realidade", ele pode se apropriar delas como "possibilidades" para fazer a vida de uma forma ou de outra. Assim, o homem vai fazendo sua vida "com" as coisas "re-ligado" ao poder do real que elas veiculam. E, na medida em que "o poder do real não se identifica com as coisas", excedendo-as, o homem se vê lançado "na direção de" de seu fundamento último. Este lançamento é uma "marcha": uma marcha "problemática" e uma marcha "real e física" (16).

(B) É uma marcha "problemática" porque seu termo depende das "rotas empreendidas": teísmo, ateísmo, agnosticismo. Em todas elas, o homem acessa ao "fundamento do poder do real", ainda que de "modo diferente": Deus, pura facticidade, realidade indeterminada. Mas ele tem que justificar intelectualmente a "via escolhida" e "essa justificação é, simultaneamente, o fundamento da opção mesma" (17).

Para Zubiri, "a justificação intelectiva do fundamento do poder do real é o que nos lança a nós mesmos por uma via que leva da pessoa humana [realidade relativamente absoluta] a uma realidade absolutamente absoluta: é o que entendemos por Deus". E, assim, "o homem encontra Deus ao realizar-se religadamente como pessoa". O "poder do real" consiste em que "as coisas reais sem ser Deus nem um momento de Deus, são, sem dúvida, reais 'em' Deus, que dizer, sua realidade é Deus ad extra". Noutras palavras, "o apoderar-se da pessoa humana pelo poder do real é, então, um apoderar-se do homem por Deus. Neste apoderar-se acontece a intelecção de Deus. Dai que toda realização pessoal humana seja precisa e formalmente a configuração optativa do ser humano a respeito de 'Deus em minha pessoa"' (17).

(C) E é uma marcha "real e física" porque não trata de um "processo meramente intelectivo, mas sim de um processo real" (16). Nessa marcha, o homem vai "tateando", "averiguando", "provando" esse fundamento. E nisso consiste, para Zubiri, "a essência mesma do que chamamos experiência" (17). Trata-se, portanto, de uma marcha experiencial em que o homem vai experimentando o "fundamento" do "poder do real".

Quando o fundamento do "poder do real" é experimentado pela "via" que leva a Deus, essa experiência "é eo ipso Deus experimentado como fundamento, é experiência de Deus". Enquanto fundamento último da vida humana, Deus não é algo meramente

\footnotetext{
${ }^{55}$ Segundo Pintor Ramos, o termo realidad designa, na filosofia de Zubiri, “o caráter mais elementar e também o mais decisivo a que qualquer problema termina remetendo". Na língua espanhola, diz ele, este termo "encerra sempre um matiz de ultimidade e rotundidade, inclusive de coercividade, propenso a conduzir a expressões dogmáticas". E, conclui: "Suspeito que a manutenção zubiriana do termo 'realidade' deve muito aos matizes peculiares e à força que este termo tem em espanhol, matizes que os termos equivalentes em outras línguas quiçá não reflitam totalmente" (PINTOR RAMOS, A. Realidad y verdade, p. 57s).
} 
"justaposto" ao homem, mas algo que, de alguma forma, "pertence" à realidade mesma do homem: "não se trata de que haja pessoa humana 'e além disso' Deus"; "Deus não é a pessoa humana, mas a pessoa humana é de alguma maneira Deus"; "Deus não inclui o homem, mas o homem inclui Deus". E, assim, o homem se constitui formalmente como "experiência de Deus" (18).

Em síntese: 1) Zubiri parte de uma análise da realidade humana como uma realidade radicalmente aberta que tem que se fazer a si mesma (abertura); 2) mostra como esta abertura tem a ver com o fato do homem apreender as coisas como "realidade" e como nesta apreensão ele se experimenta paradoxalmente como "desligado" de todas as coisas e "religado" ao "poder do real" que as coisas veiculam (religação); 3) mostra ainda como, na medida em que fundamenta as coisas sem se identificar com elas, excedendo-as, o "poder do real" lança o homem na direção de seu fundamento último e que esse fundamento último pode ser apreendido e justificado por vias distintas: teísta, ateísta e agnóstica (fundamento); 4) propõe/justifica a via teísta como a via que nos leva do homem como realidade "relativamente absoluta" a Deus como realidade "absolutamente absoluta" (Deus); 5) e, assim, apreende e justifica Deus como fundamento último de toda realidade; fundamento que possibilita e impele o homem a se realizar a si mesmo (fundamento, possibilidade, impelência).

\subsection{Apreciação crítica}

Em sua abordagem filosófica sobre Deus, Zubiri não parte nem do cosmos (abordagem cosmológica) nem de uma dimensão da vida humana (abordagem antropológica), mas da religação como fato real, total e radical da vida humana em seu enfrentamento com as coisas (abordagem práxica).

Essa abordagem tem o mérito de superar os reducionismos cosmológicos e antropológicos, tomando a realidade em sua complexidade e unidade radical tal como aparece na vida humana (práxis) e partindo de um fato verificável na própria vida humana em seu processo de autorrealização histórica (religação). Tem também o mérito de falar de Deus não apenas como fundamento do mundo natural, deixando de fora a realidade humana (abordagem cosmológica), nem apenas como fundamento da realidade humana, segregada do mundo natural (abordagem antropológica), mas como fundamento último da realidade em seu todo. É que "o Deus a quem todos nos referimos não é apenas possibilitante e impelente (seja de um modo intelectual, volente ou sentimental), mas é também formalmente e ao mesmo tempo a ultimidade do real" ${ }_{56}$ : "realidade absolutamente absoluta, realidade última, possibilitante e impelente" 57 .

Além do mais, essa abordagem permite tomar em sério o dinamismo histórico desencadeado pelas experiências concretas/particulares desse fundamento último nas mais diversas tradições religiosas (religião como "plasmação da religação"), particularmente em seu potencial histórico-libertador (religião e libertação) ${ }^{58}$, não obstante o risco permanente de sua instrumentalização ideológica pelos grupos e setores dominantes da sociedade.

\footnotetext{
${ }^{56}$ ZUBIRI, X. El hombre y Dios. Op. cit., p. 127.

${ }^{57}$ ZUBIRI, X. El hombre y Dios, p. 132.

${ }^{58} \mathrm{Cf}$. GONZÁLEZ, A. Introducción a la práctica de la filosofia, p. 379-385.
} 


\section{REFERÊNCIAS}

ANSELMO DE CANTUÁRIA. Proslógio. Porto Alegre: Concreta, 2016.

ANZENBACHER, A. Introdução à filosofia ocidental. Petrópolis: Vozes, 2009.

CORETH, E. Deus no pensamento filosófico. São Paulo: Loyola, 2009.

DESCARTES, R. Os Pensadores. São Paulo: Abril. Cultural e Industrial, 1973.

ELLACURÍA, I. Filosofía de la realidade histórica. San Salvador: UCA, 1999.

GAUNILO. Livro escrito a favor de um insensato. In: ANSELMO DE CANTUÁRIA. Proslógio. Porto Alegre: Concreta, 2016. p. 83-93.

GILSON, E. Introdução à filosofia cristã. Santo André: Academia Cristã, 2014.

GONZÁLEZ, A. Introducción a la práctica de la filosofia. Texto de iniciación. San Salvador: UCA, 2005.

JAEGER, W. La teologia de los primeiros filósofos griegos. México: Fondo de Cultura Económica, 1998.

JORDAN, J. (Org.). Filosofia da Religião. São Paulo: Paulinas, 2015.

KANT, I. Crítica da Razão Pura. São Paulo: Nova Cultural, 1996.

LEBRUN, G. "Prefácio e notas”. In: DESCARTES, R. Os Pensadores. São Paulo: Abril S.A. Cultural e Industrial, 1973.

LIMA VAZ, H.C. Escritos de Filosofia: Problemas de Fronteira. São Paulo: Loyola, 1986.

OLIVEIRA, M.; ALMEIDA, C. (Org.). O Deus dos filósofos modernos. Petrópolis: Vozes, 2002.

. (Org.). O Deus dos filósofos contemporâneos. Petrópolis: Vozes, 2002.

NICOLAS, J.-H. O Deus único: introdução e notas. In: TOMÁS DE AQUINO, T. Suma Teológica. Parte I. Volume 1. São Paulo: Loyola, 2001.

NOUGUÉ, C. Apresentação. In: TOMÁS DE AQUINO. Compêndio de Teologia. Porto Alegre: Concreta, 2015, 25-69.

PANNENBERG, W. Filosofia e Teologia: Tensões e convergências de uma busca comum. São Paulo: Paulinas, 2008.

PENZO, G.; GIBELlinI, R. Deus na filosofia do século XX. São Paulo: Loyola, 1998.

PINTOR RAMOS, A. Realidad y verdade: Las bases de la filosofia de Zubiri. Salamanca: Pontifícia Universidad, 1994.

ROWE, W.L. Introdução à filosofia da religião. Lisboa: Verbo, 2011.

SANTO AGOSTINHO. A Trindade. São Paulo: Paulus, 1994.

TOMÁS DE AQUINO. Suma Teológica. Parte I. Volume 1. São Paulo: Loyola, 2001.

WILKINSON, M. B.; CAMPBELL, H. N. Filosofia da religião: Uma introdução. São Paulo: Paulinas, 2014.

ZUBIRI, X. El hombre y Dios. Madrid: Alianza Editorial, 2003.

. El problema filosófico de la historia de las religiones. Madrid: Alianza Editorial, 2006. El problema teologal del hombre: Cristianismo. Madrid: Alianza Editorial, 1999.

O problema teologal do homem. In: OLIVEIRA, M.; ALMEIDA, C. (Org.). O Deus dos filósofos modernos. Petrópolis: Vozes, 2002, 13-20.

Recebido em: 12/03/2017

Aprovado em: 23/10/2017

Correspondência para:

Francisco de Aquino Júnior

Caixa Postal, 27

62930-000 Limoeiro do Norte, CE, Brasil 